\title{
The gap between food-based dietary guidelines and usual food consumption in Belgium, 2004
}

\author{
Stefanie Vandevijuere ${ }^{1, *}$, Stéphanie De Vriese ${ }^{1}$, Inge Huybrechts ${ }^{2}$, Michel Moreau', \\ Elisabeth Temme', Stefaan De Henauw², Guy De Backer², Marcel Kornitzer ${ }^{3}$, \\ Alain Leveque ${ }^{3}$ and Herman Van Oyen ${ }^{1}$ \\ 'Scientific Institute of Public Health, Unit of Epidemiology, J. Wytsmanstraat 14, B-1050 Brussels, Belgium: \\ ${ }^{2}$ Ghent University, Department of Public Health, Ghent, Belgium: ${ }^{3}$ Ecole de Santé Publique, Faculté de \\ Médecine, Université Libre de Bruxelles, Brussels, Belgium
}

Submitted 14 November 2007: Accepted 25 February 2008: First published online 22 April 2008

\begin{abstract}
Objective: To evaluate the gap between food-based dietary guidelines (FBDG) and the usual food consumption in Belgium.

Design and setting: Information on food intake was collected with two nonconsecutive $24 \mathrm{~h}$ recalls, using the validated software package EPIC-SOFT in combination with a self-administered FFQ. Habitual food intake was estimated by the Nusser method. Physical activity was evaluated according to the International Physical Activity Questionnaire.

Subjects: A representative sample of the Belgian population aged 15 years and older was randomly selected from the National Register using a multistage stratified procedure. Dietary information was obtained from 3245 individuals.

Results: Food intakes deviated significantly from the recommendations. In particular, fruit $(118 \mathrm{~g} / \mathrm{d})$ and vegetable $(138 \mathrm{~g} / \mathrm{d})$ consumption and intake of dairy and $\mathrm{Ca}$-enriched soya products $(159 \mathrm{~g} / \mathrm{d})$ were inadequate. Consumption of energy-dense, nutrient-poor foods (soft drinks, alcohol and snacks) was excessive $(481 \mathrm{~g} / \mathrm{d})$. There were important age and gender differences. Fruit, vegetable and spreadable fat consumption was lowest, while consumption of dairy, starchy and energy-dense, nutrient-poor foods was highest among the youngest age group. Men consumed more animal and starchy foods than women, who consumed more fruits. There were only slight differences by education level.

Conclusion: Food intakes differed substantially from the FBDG. Improvement of the Belgian food pattern, in particular among the youngest age group, is necessary for a better prevention of diet-related diseases. In addition, continuous or regular monitoring is crucial to permit trend analyses and to plan effective education or intervention strategies.
\end{abstract}

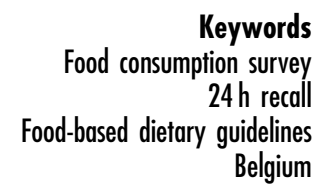

guidelines
Belgium was one of the few European countries lacking a systematic survey on the dietary habits of its inhabitants for many years. The last national study that included a dietary assessment was the Belgian Interuniversity Research on Nutrition and Health ${ }^{(1)}$ study, held from 1980 to 1985 . However, as dietary habits are changing continuously over time, it is important to be aware of current dietary patterns in order to develop effective policies on nutrition. Therefore, in 2004, the Ministry of Public Health, Environment and Food Safety initiated the first Belgian National Food Consumption Survey (BNFCS). One of the aims of the BNFCS is to monitor the adequacy of food intakes within the Belgian population. The objective of the present paper is to compare the usual food group intakes with the food-based dietary guidelines
(FBDG) and to determine the proportion of the population meeting these recommendations. Differences in intakes between different subgroups of the population (as defined by sociodemographic and age variables) are also investigated.

FBDG were developed ${ }^{(2)}$ and used internationally to express the principles of a balanced diet in terms of foods $^{(3-10)}$ and to reduce the prevalence of obesity ${ }^{(11)}$ and diet-related diseases. These guidelines are a more practical tool compared with the nutrient reference values, set at (inter-) national level ${ }^{(12,13)}$. In Belgium, a food triangle and a food pyramid were developed by the regional health authorities which are responsible for health promotion ${ }^{(14,15)}$.

Although both guidelines are similar, in the present paper food group intakes are compared with the 
recommendations proposed by the Flemish food triangle, since the latter describes the guidelines in terms of both the number of pieces and the amount (grams or millilitres). According to the food triangle a healthy diet is based on balance, variation and moderation.

The triangle is composed of eight food groups: water; grains and potatoes; vegetables; fruits; dairy (including cheese) and Ca-enriched soya products; meat, fish, eggs, legumes, nuts and meat substitutes; fats; and energy-dense, nutrient-poor foods.

The water food group includes water, coffee, tea and broth. All groups, except energy-dense, nutrient-poor foods, are necessary for a healthy diet. The bigger the surface of a particular food group in the triangle, the bigger the daily consumption of that food group should be relative to the other food groups.

In 2005 a new model was developed which takes physical activity into account as well ${ }^{(16)}$. In this newly proposed model the dietary guidelines remain the same but an additional recommendation for physical activity, expressed by the base of the triangle, is added. According to this 'active' model, a person should accumulate at least half an hour of physical activity of at least moderate intensity on most if not all days of the week by performing the activity for at least $10 \mathrm{~min}$ at a time.

\section{Design and methods}

The study design of the present survey followed to a large extent the recommendations of the European Food Consumption Survey Method (EFCOSUM) project ${ }^{(17)}$, which envisaged the formulation of recommendations to harmonise the methodology of collection of food consumption data across Europe. The study was approved by the ethical committee of the Scientific Institute of Public Health. An in-depth description of the study design and the methodology used is given elsewhere ${ }^{(18)}$.

\section{Sampling design}

A representative sample of the Belgian population aged 15 years and older was randomly selected from the National Register. The sample size was defined by sample size calculations based on an estimated mean intake of different nutrients to fall within a 5\% interval around the true population mean with a $95 \%$ probability.

The sampling method followed a multistage stratified procedure. The strata were categorised by four age groups (15-18 years, 19-59 years, 60-74 years, $\geq 75$ years) and both genders. Belgium was divided into three regions and eleven provincial strata.

The participants were sampled in a way that the population densities of the region, the provinces and the municipalities were taken into account. For each selected individual, three individuals were selected beforehand who could serve as replacements in case the selected individual would not participate in the survey. The selected individuals and their substitutes lived in the same statistical sector of the same municipality, in a household of the same size and had the same age and gender.

Institutionalised persons, individuals unable to speak one of the three national languages (Dutch, French or German) and individuals physically or mentally unable to be interviewed were excluded.

Of the 7543 invited and contactable individuals, 42\% participated in the study. Participation rate was $40.6 \%$ for men $43.4 \%$ for women. The main reasons for not participating were lack of interest $(54 \%)$, lack of time (17\%) and health problems (12\%).

\section{Study design}

Participants were invited to take part in the study by a letter and leaflet. They were visited twice by a trained dietitian. At the first visit the participants completed a face-to-face questionnaire about general health, lifestyle and physical activity. Physical activity was evaluated according to the International Physical Activity Questionnaire (IPAQ) ${ }^{(19)}$. A $24 \mathrm{~h}$ recall assessed the previous day's dietary intake. During the second visit, two to eight weeks later, a second $24 \mathrm{~h}$ recall was performed. In the time between these two visits, participants were asked to complete an FFQ. The dietitians checked the questionnaires for completeness. The one-year survey was distributed equally over all seasons and days of the week.

\section{Dietary assessment}

During the $24 \mathrm{~h}$ recall the participants reported the types and quantities of all foods and beverages consumed during the preceding day. To obtain standardised $24 \mathrm{~h}$ recall interviews, the validated software package EPICSOFT was used, which is designed for uniform data collection in the ten countries participating in the European Prospective Investigation into Cancer and Nutrition (EPIC) $^{(20)}$.

The software enables very detailed descriptions and quantities of foods and supplements consumed and recipes used to be obtained in a standardised way. Quantification of the consumed foods is supported by a picture book that contains photographs of foods in different portion sizes.

All foods and ingredients reported were assigned to the appropriate triangle group and the quantity of all food groups consumed was expressed in $\mathrm{g} / \mathrm{d}$. To allow the comparison of portion sizes with the FBDG, the portion size of some reported foods had to be converted into an equivalent of another food using conversion factors proposed in the food guide ${ }^{(15)}$. For rice, for example, the portion size had to be converted to an equivalent portion size of potatoes as the recommendation is expressed in g potatoes/d. 


\section{Statistical analyses}

Because of day-to-day variations in individual food intakes, a large number of days of intake data are typically needed to determine usual food intakes. It is seldom feasible to collect these required long-term data for each person. Therefore, a statistical modelling method was needed that accounted for within-individual variation in food intakes while requiring relatively few days of intake data per individual. The present study used the Nusser method $^{(21)}$, which is recommended by the Institute of Medicine ${ }^{(22)}$. With this method the total variance is adjusted for the intra-individual variances of day-to-day variability. In addition, data were transformed to a normal distribution. This statistical method for estimating usual intake distributions and the proportion below or above defined cut-off values was developed at Iowa State University $^{(21,23)}$. The software program used to carry out the method was Software for Intake Distribution Estimation $\left(\mathrm{C}\right.$-side) ${ }^{(24)}$.

The reported food intakes were weighted and adjusted for interview day, season and, in the case of education level, adjusted for the age and sex distribution of the Belgian population.

To assess the percentage of persons consuming certain foods on a daily basis, FFQ data were used.

The IPAQ recommendations were used to calculate the percentage of persons physically active enough to experience health-enhancing effects ${ }^{(19)}$. According to IPAQ, health-enhancing physical activity means vigorous-intensity activity on at least $3 \mathrm{~d}$ of the week achieving a minimum total physical activity of at least $1500 \mathrm{MET}-\mathrm{min} /$ week, or $7 \mathrm{~d}$ or more of any combination of walking, moderate-intensity or vigorous-intensity activities achieving a minimum total physical activity of at least 3000 MET-min/week. The MET (metabolic energy equivalent task) for an activity is a multiple of the RMR and MET-min are equivalent to kilocalories for a person weighing $60 \mathrm{~kg}$.

\section{Results}

\section{Mean usual daily intake of the major food groups}

The mean daily intake of beverages (water, coffee, tea and broth) was 1202 (SD 593) $\mathrm{ml}$. The youngest age group had the lowest daily consumption of beverages $(P<0 \cdot 001)$ (Table 1$)$.

The majority of the Belgian population (82.3\%) consumed bread products or breakfast cereals on a daily basis and more than half of them (58.6\%) consumed potatoes, rice or pasta on a daily basis. The mean daily intake of bread and breakfast cereals was 133 (SD 59) g while the average intake of potatoes, rice and pasta was 307 (SD 146) g. Men consumed more of these starchy products than women $(P<0 \cdot 001)$ (Table 2$)$ and the consumption of these products decreased with age $(P<0 \cdot 001)$ (Table 1$)$.

Only $37 \cdot 7 \%$ of the Belgian population consumed vegetables on a daily basis. The mean daily intake of vegetables was 138 (SD 53) g. There was no real difference in daily intake by gender $(P>0 \cdot 05)$ (Table 2$)$, although women consumed vegetables more frequently than men (daily consumers: $43 \cdot 8 \%$ v. $31 \cdot 3 \%$ ). The youngest and the oldest age groups consumed the least vegetables $(P<0 \cdot 001)$ (Table 1$)$. Persons with a higher secondary or higher education consumed more vegetables than

Table 1 Mean (SD) food intakest (g/d) of the Belgian population, by age group, compared with the general recommendations of the Flemish food triangle ${ }^{(15)}$

\begin{tabular}{|c|c|c|c|c|c|c|c|c|c|c|c|c|c|}
\hline \multirow[b]{3}{*}{ Food group } & \multirow[b]{3}{*}{ Recommendation } & & & & \multicolumn{9}{|c|}{ Age group } \\
\hline & & \multicolumn{3}{|c|}{ Total population } & \multicolumn{2}{|c|}{$15-18$ years } & \multicolumn{2}{|c|}{$19-59$ years } & \multicolumn{2}{|c|}{$60-74$ years } & \multicolumn{2}{|c|}{$\geq 75$ years } & \multirow[b]{2}{*}{$P$} \\
\hline & & Mean & SD & $n \ddagger$ & Mean & SD & Mean & SD & Mean & SD & Mean & SD & \\
\hline Liquids (water, coffee, tea, broth) & $\geq 1500 \mathrm{ml} / \mathrm{d}$ & 1202 & 593 & 3018 & 731 & 422 & 1278 & 601 & 1185 & 505 & 969 & 398 & *** \\
\hline GP: bread and breakfast cereals§ & $175-420 \mathrm{~g} / \mathrm{d}$ & 133 & 59 & 3037 & 146 & 59 & 137 & 59 & 123 & 52 & 111 & 48 & *** \\
\hline GP: potatoes/rice/pasta§ & $210-350 \mathrm{~g} / \mathrm{d}$ & 307 & 146 & 2972 & 369 & 112 & 339 & 109 & 221 & 114 & 200 & 139 & 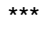 \\
\hline Vegetables (raw) $\|$ & $\geq 350 \mathrm{~g} / \mathrm{d}$ & 138 & 53 & 2906 & 111 & 37 & 141 & 51 & 144 & 49 & 120 & 51 & *** \\
\hline Fruits & $\geq 250 \mathrm{~g} / \mathrm{dtt}$ & 118 & 84 & 2244 & 82 & 59 & 111 & 77 & 145 & 90 & 141 & 92 & *** \\
\hline Dairy and soya products & $450-600 \mathrm{~g} / \mathrm{d}$ & 159 & 127 & 2582 & 206 & 140 & 164 & 125 & 129 & 103 & 141 & 109 & *** \\
\hline Cheese & $20-40 \mathrm{~g} / \mathrm{d}$ & 30 & 18 & 2295 & 28 & 15 & 32 & 18 & 26 & 17 & 25 & 16 & *** \\
\hline Meat/fish/eggs/legumes/nuts/substitutes & $\leq 100 \mathrm{~g} / \mathrm{d}$ & 161 & 56 & 3061 & 144 & 47 & 167 & 59 & 161 & 47 & 137 & 42 & *** \\
\hline Spreadable fat & $\leq 60 \mathrm{~g} / \mathrm{d}$ & 21 & 23 & 2370 & 10 & 10 & 19 & 20 & 29 & 25 & 34 & 26 & *** \\
\hline Nutrient-poor foods (alcohol included) & $<100 \mathrm{~g} / \mathrm{d} \neq \ddagger$ & 481 & 395 & 3069 & 627 & 411 & 529 & 409 & 371 & 273 & 238 & 169 & *** \\
\hline Nutrient-poor foods (alcohol excluded) & $<100 \mathrm{~g} / \mathrm{d} \neq \ddagger$ & 266 & 244 & 3053 & 534 & 339 & 295 & 255 & 149 & 90 & 115 & 68 & *** \\
\hline
\end{tabular}

GP, grains and potatoes.

Significance level of the differences between the four age groups, according to ANOVA (two-sided): ${ }^{\star} P<0 \cdot 05,{ }^{\star \star} P<0 \cdot 01,{ }^{\star \star \star} P<0 \cdot 001$.

tMean food intakes are adjusted for interview day and season.

$\ddagger$ Number of persons consuming items of the specified food group at least once (of a total of 3083).

$\S$ These products belong to the same general food group (grains and potatoes) but two different recommendations were formulated because potatoes are usually consumed as part of a hot meal and thus practically can only be interchanged with pasta or rice, while bread and breakfast cereals are usually consumed as part of a cold meal and thus practically cannot be interchanged with potatoes, rice or pasta.

$\|$ Excluding vegetable soups and juices (soups and juices cannot replace vegetables in terms of fibre, vitamin and mineral content).

- Excluding fruit juices and olives (however, the recommendation states that maximum 1 piece of fruit $(=125 \mathrm{~g})$ per day may be interchanged with juice)

t+The recommended intake for adolescents in the $15-18$ year age group is $\geq 375 \mathrm{~g} / \mathrm{d}$.

$\ddagger \ddagger$ According to the recommendation the intake should approach $0 \mathrm{~g} / \mathrm{d}$. 
Table 2 Mean (SD) food intakest ( $\mathrm{g} / \mathrm{d}$ ) of the Belgian population, by gender, compared with the general recommendations of the Flemish food triangle $e^{(15)}$

\begin{tabular}{|c|c|c|c|c|c|c|c|c|c|}
\hline \multirow[b]{3}{*}{ Food group } & \multirow[b]{3}{*}{ Recommendation } & \multirow{2}{*}{\multicolumn{3}{|c|}{ Total population }} & \multicolumn{5}{|c|}{ Gender } \\
\hline & & & & & \multicolumn{2}{|c|}{ Men } & \multicolumn{2}{|c|}{ Women } & \multirow[b]{2}{*}{$P$} \\
\hline & & Mean & $\mathrm{SD}$ & $n \ddagger$ & Mean & SD & Mean & SD & \\
\hline Liquids (water, coffee, tea, broth) & $\geq 1500 \mathrm{ml} / \mathrm{d}$ & 1202 & 593 & 3018 & 1156 & 598 & 1235 & 580 & *** \\
\hline GP: bread and breakfast cereals $\S$ & $175-420 \mathrm{~g} / \mathrm{d}$ & 133 & 59 & 3037 & 157 & 65 & 111 & 42 & *** \\
\hline GP: potatoes/rice/pasta $\S$ & $210-350 \mathrm{~g} / \mathrm{d}$ & 307 & 146 & 2972 & 366 & 154 & 245 & 106 & 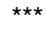 \\
\hline Vegetables (raw)\| & $\geq 350 \mathrm{~g} / \mathrm{d}$ & 138 & 53 & 2906 & 138 & 46 & 138 & 59 & \\
\hline Fruits & $\geq 250 \mathrm{~g} / \mathrm{dtt}$ & 118 & 84 & 2244 & 99 & 85 & 134 & 77 & $\star \star \star *$ \\
\hline Dairy and soya products & $450-600 \mathrm{~g} / \mathrm{d}$ & 159 & 127 & 2582 & 166 & 144 & 152 & 111 & *** \\
\hline Cheese & $20-40 \mathrm{~g} / \mathrm{d}$ & 30 & 18 & 2295 & 34 & 22 & 27 & 14 & *** \\
\hline Meat/fish/eggs/legumes/nuts/substitutes & $\leq 100 \mathrm{~g} / \mathrm{d}$ & 161 & 56 & 3061 & 204 & 64 & 127 & 33 & *** \\
\hline Spreadable fat & $\leq 60 \mathrm{~g} / \mathrm{d}$ & 21 & 23 & 2370 & 26 & 26 & 16 & 17 & 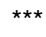 \\
\hline Nutrient-poor foods (alcohol included) & $<100 \mathrm{~g} / \mathrm{d} \neq \ddagger$ & 481 & 395 & 3069 & 678 & 498 & 300 & 206 & *** \\
\hline Nutrient-poor foods (alcohol excluded) & $<100 \mathrm{~g} / \mathrm{d} \neq \ddagger$ & 266 & 244 & 3053 & 343 & 317 & 197 & 164 & *** \\
\hline
\end{tabular}

GP, grains and potatoes.

Significance level of the differences between men and women according to the $t$ test (two-sided): ${ }^{\star} P<0 \cdot 05,{ }^{\star \star} P<0 \cdot 01,{ }^{\star \star \star} P<0 \cdot 001$.

tMean food intakes are adjusted for interview day and season.

$\ddagger$ Number of persons consuming items of the specified food group at least once (of a total of 3083).

\$These products belong to the same general food group (grains and potatoes) but two different recommendations were formulated because potatoes are usually consumed as part of a hot meal and thus practically can only be interchanged with pasta or rice, while bread and breakfast cereals are usually consumed as part of a cold meal and thus practically cannot be interchanged with potatoes, rice or pasta.

$\|$ Excluding vegetable soups and juices (soups and juices cannot replace vegetables in terms of fibre, vitamin and mineral content).

- Excluding fruit juices and olives (however, the recommendation states that maximum 1 piece of fruit (=125 g) per day may be interchanged with juice).

t+The recommended intake for adolescents in the $15-18$ year age group is $\geq 375 \mathrm{~g} / \mathrm{d}$.

$\ddagger \ddagger$ According to the recommendation the intake should approach $0 \mathrm{~g} / \mathrm{d}$.

Table 3 Mean (SD) food intakest ( $\mathrm{g} / \mathrm{d}$ ) of the Belgian population, by education level, compared with the general recommendations of the Flemish food triangle ${ }^{(15)}$

\begin{tabular}{|c|c|c|c|c|c|c|c|c|c|c|c|c|c|}
\hline \multirow[b]{3}{*}{ Food group } & \multirow[b]{3}{*}{ Recommendation } & & & & \multicolumn{9}{|c|}{ Education level§ } \\
\hline & & \multicolumn{3}{|c|}{ Total population } & \multicolumn{2}{|c|}{1} & \multicolumn{2}{|c|}{2} & \multicolumn{2}{|l|}{3} & \multicolumn{2}{|c|}{4} & \multirow[b]{2}{*}{$P$} \\
\hline & & Mean & SD & $n \ddagger$ & Mean & SD & Mean & SD & Mean & SD & Mean & SD & \\
\hline Liquids (water, coffee, tea, broth) & $\geq 1500 \mathrm{ml} / \mathrm{d}$ & 1202 & 593 & 3018 & 1124 & 510 & 1220 & 598 & 1148 & 502 & 1251 & 596 & $\star \star * *$ \\
\hline GP: bread and breakfast cereals $\|$ & $175-420 \mathrm{~g} / \mathrm{d}$ & 133 & 59 & 3037 & 123 & 55 & 139 & 53 & 133 & 48 & 131 & 45 & $\star \star * \star$ \\
\hline GP: potatoes/rice/pasta\| & $210-350 \mathrm{~g} / \mathrm{d}$ & 307 & 146 & 2972 & 246 & 108 & 297 & 96 & 336 & 125 & 306 & 103 & $\star \star * *$ \\
\hline Vegetables (raw) & $\geq 350 \mathrm{~g} / \mathrm{d}$ & 138 & 53 & 2906 & 127 & 49 & 122 & 44 & 144 & 54 & 156 & 49 & $\star \star * *$ \\
\hline Fruitstt & $\geq 250 \mathrm{~g} / \mathrm{d} \ddagger \ddagger$ & 118 & 84 & 2244 & 121 & 90 & 111 & 84 & 128 & 95 & 119 & 75 & $\star \star \star *$ \\
\hline Dairy and soya products & $450-600 \mathrm{~g} / \mathrm{d}$ & 159 & 127 & 2582 & 140 & 116 & 154 & 118 & 132 & 91 & 175 & 122 & $\star \star \star ~$ \\
\hline Cheese & $20-40 \mathrm{~g} / \mathrm{d}$ & 30 & 18 & 2295 & 26 & 16 & 29 & 18 & 31 & 19 & 33 & 16 & $\star \star \star *$ \\
\hline Meat/fish/eggs/legumes/nuts/substitutes & $\leq 100 \mathrm{~g} / \mathrm{d}$ & 161 & 56 & 3061 & 162 & 47 & 175 & 54 & 143 & 35 & 152 & 36 & $\star \star \star ~$ \\
\hline Spreadable fat & $\leq 60 \mathrm{~g} / \mathrm{d}$ & 21 & 23 & 2370 & 27 & 23 & 23 & 21 & 19 & 19 & 16 & 15 & $\star * *$ \\
\hline Nutrient-poor foods (alcohol included) & $<100 \mathrm{~g} / \mathrm{d} \S \S$ & 481 & 395 & 3069 & 364 & 267 & 561 & 387 & 461 & 268 & 444 & 257 & $\star \star * *$ \\
\hline Nutrient-poor foods (alcohol excluded) & $<100 \mathrm{~g} / \mathrm{d} \S \S$ & 266 & 244 & 3053 & 200 & 141 & 312 & 242 & 243 & 162 & 223 & 144 & $\star \star *$ \\
\hline
\end{tabular}

GP, grains and potatoes.

Significance level of the differences between the four education level groups according to ANOVA (two-sided): ${ }^{\star} P<0 \cdot 05,{ }^{\star \star} P<0 \cdot 01,{ }^{\star \star \star} P<0 \cdot 001$.

+Mean food intakes are adjusted for interview day, season and the age and sex distribution of the Belgian population.

†Number of persons consuming items of the specified food group at least once (of a total of 3083).

EEducation level: $1=$ no education or only lower secondary education; 2 = vocational education; $3=$ higher secondary education; $4=$ higher education.

IThese products belong to the same general food group (grains and potatoes) but two different recommendations were formulated because potatoes are usually consumed as part of a hot meal and thus practically can only be interchanged with pasta or rice, while bread and breakfast cereals are usually consumed as part of a cold meal and thus practically cannot be interchanged with potatoes, rice or pasta.

-Excluding vegetable soups and vegetable juices (soups and juices cannot replace vegetables in terms of fibre, vitamin and mineral content).

t+Excluding fruit juices and olives (however, the recommendation states that maximum 1 piece of fruit $(=125 \mathrm{~g})$ per day may be interchanged with juice).

$\$ \neq$ The recommended intake for adolescents in the age group 15-18 years is $\geq 375 \mathrm{~g} / \mathrm{d}$.

$\S \S$ According to the recommendation the intake should approach $0 \mathrm{~g} / \mathrm{d}$, but this is not realistic.

persons with a lower secondary or vocational education $(P<0 \cdot 001)$ (Table 3).

Less than half of the population $(47 \cdot 3 \%)$ consumed fruits on a daily basis. The mean daily intake of fruits was 118 (SD 84) g. Women consumed fruits more frequently than men (daily consumers: $56 \cdot 1 \% v$. 38.0\%) and their mean daily fruit consumption was higher $(P<0 \cdot 001)$ (Table 2). Fruit consumption increased somewhat with increasing age $(P<0 \cdot 001)$ (Table 1$)$.

About two-thirds of Belgians consumed dairy or Ca-enriched soya products on a daily basis, whereas $79 \cdot 3 \%$ of the Belgian population never consumed soya products. 
The mean daily intake of dairy and soya products (cheeses excluded) was 159 (sD 127) g. Women consumed these products more frequently than men (daily consumers: $77 \cdot 0 \% v \cdot 71 \cdot 2 \%)$ but their mean daily intake was somewhat lower $(P<0 \cdot 001)$ (Table 2$)$. The average daily intake of dairy and soya products was highest among the youngest age group $(P<0 \cdot 001)$ (Table 1$)$.

Less than a quarter of the population consumed cheese on a daily basis but the average daily intake of cheese was 30 (SD 18) g, which is higher than the lower limit of the recommendation $(20 \mathrm{~g} / \mathrm{d})$. The mean daily intake of cheese was somewhat lower for women than for men $(P<0.001)$ (Table 2) and increased with education level $(P<0 \cdot 001)$ (Table 3$)$.

In total $88.9 \%$ of the population consumed meat, fish, eggs, legumes, nuts or meat substitutes at least once a day. The mean total daily intake amounted to 161 (SD 56) g. The mean daily intake of fish and crustaceans was 24 (SD 14) g. Men consumed more of these products than women $(P<0 \cdot 001)$ (Table 2$)$. Persons with a lower education (lower secondary or vocational) consumed more of these products than those with a higher education $(P<0 \cdot 001)$ (Table 3$)$.

More than half of the respondents used spreadable fats on a daily basis. The mean daily intake was 21 (SD 23) $\mathrm{g}$ and was lower for women than men $(P<0 \cdot 001)$ (Table 2$)$. The intake of spreadable fats increased with age $(P<0.001)$ (Table 1$)$ and decreased with education level $(P<0 \cdot 001)$ (Table 3$)$.

Nutrient-poor, energy-dense foods are not necessary in a balanced diet and are discouraged. However, the mean daily intake of these products was 481 (sD 395) g (alcohol included) and 266 (sD 244) g (alcohol excluded). Women consumed fewer energy-dense, nutrient-poor foods than men $(P<0 \cdot 001)$ (Table 2). Persons with the lowest education level had the lowest consumption of these foods compared with the other education levels $(P<0 \cdot 001)$ (Table 3). The consumption of energy-dense, nutrient-poor foods decreased clearly with age $(P<0 \cdot 001)$ (Table 1$)$. In particular, consumption of soft drinks was high within the 15-18 year age group (Fig. 1) and decreased with age. Men consumed more alcohol than women and the consumption of alcohol was lowest in the youngest and the oldest age groups (Fig. 1).

\section{Percentage of persons reaching the recommendations}

The base of the food triangle (Fig. 2) describes the recommendation for physical activity. According to the IPAQ guidelines, the major part of the population was inactive $(41 \cdot 1 \%)$ or only minimally active $(31 \cdot 2 \%)$. Only $27 \cdot 7 \%$ of the population was physically active enough to experience health-enhancing effects. The percentage of persons physically active enough to experience healthenhancing effects was higher for men than for women and was lowest among the oldest age group (Fig. 3).
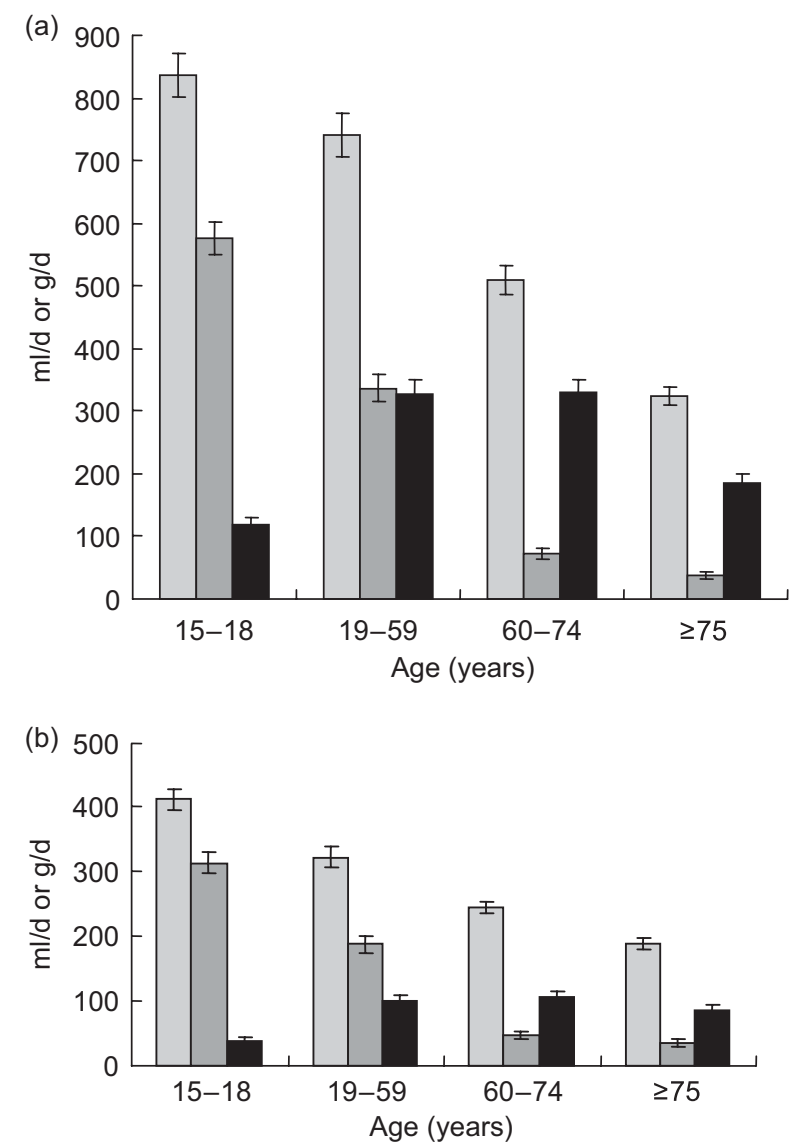

Fig. 1 Daily intake $(\mathrm{ml} / \mathrm{d}$ or $\mathrm{g} / \mathrm{d})$ of total nutrient-poor, energydense foods $(\sqsubset)$, soft drinks ( $\square$ ) and alcoholic beverages ( $\square$ ) for the male (a) and female (b) Belgian population by age group. Values are means with their standard deviations represented by vertical bars

The mean daily intake of beverages (water, broth, coffee and tea) amounted to $80 \%$ of the recommended intake. This recommendation was met by only $26 \cdot 2 \%$ of the Belgian population. Only $2 \cdot 8 \%$ of the men in the youngest age category (15-18 years) reached this recommendation.

Of the Belgian population $20.7 \%$ met the recommendation of eating at least $175 \mathrm{~g}$ bread or breakfast cereals daily. Fewer women met this recommendation $(7 \cdot 3 \%)$ than men $(34 \cdot 2 \%)$. The majority of the Belgian population $(72.9 \%)$ reached the recommendation of eating at least $210 \mathrm{~g}$ potatoes, rice or pasta daily. Younger age groups met these recommendations better than the older age groups.

The mean intake of vegetables was inadequate $(138 \mathrm{~g} / \mathrm{d})$ and far below the recommended intake of at least $350 \mathrm{~g} / \mathrm{d}$. Only one in 1000 persons met the recommendation. Even when vegetable soups and juices were included, only $13.0 \%$ of women and $8.8 \%$ of men complied with this recommendation. In the 15-18 year age group hardly anyone met the recommendation, even after including soups and juices.

The same applied for fruit consumption: the mean intake hardly reached $118 \mathrm{~g} / \mathrm{d}$ while the lower limit of the recommendation is $250 \mathrm{~g} / \mathrm{d}$. Only $7 \cdot 6 \%$ of the population 


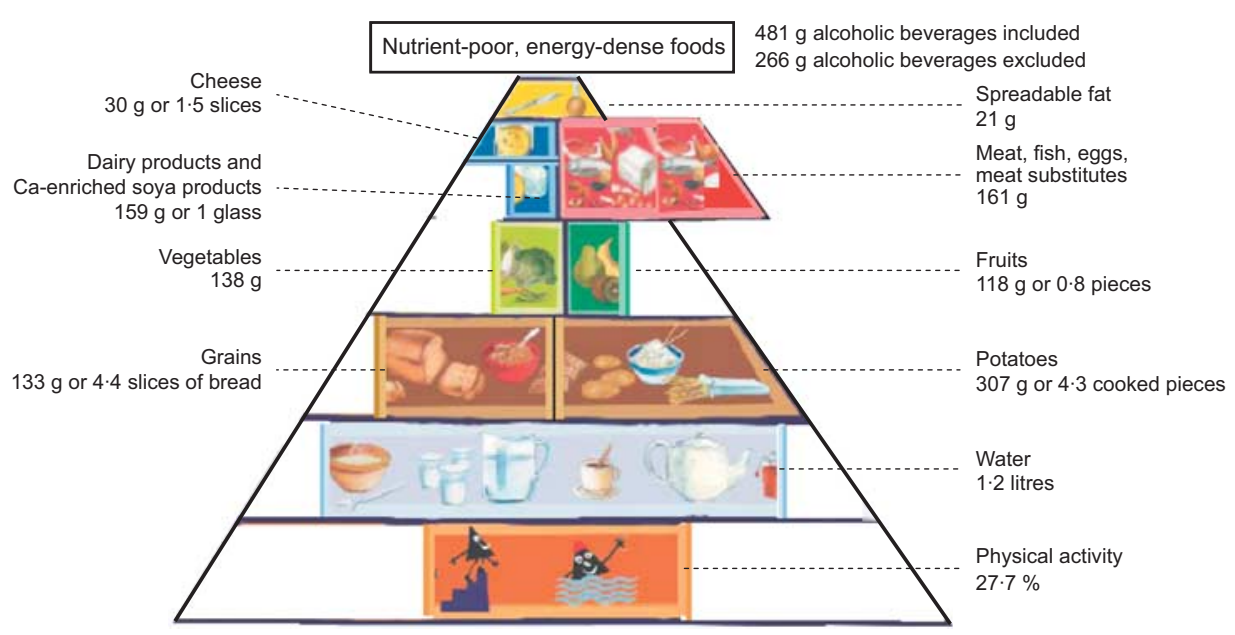

Fig. 2 The Flemish 'active' food triangle and the extent to which the average food intakes deviate from the recommendations. If the Belgian population attained all recommendations, all areas of the observed food triangle would have the same surface as the areas of the recommended food triangle. (C) VIG

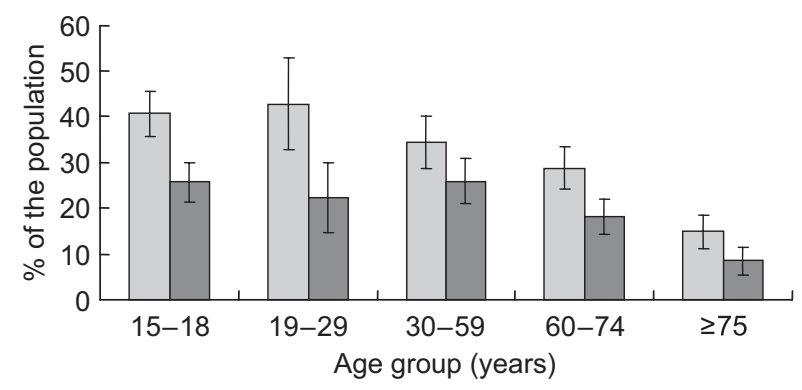

Fig. 3 Percentage of the Belgian population ( $\sqsubset$, men; $\square$, women) physically active enough to experience health-enhancing effects, by age group. Values are means with their standard deviations represented by vertical bars

met this recommendation. Adolescents (15-18 years) are recommended to consume at least $375 \mathrm{~g}$ fruit daily. None of them met this recommendation. When fruit juices were included, only $21 \cdot 6 \%$ of the general population met the recommendation $(250 \mathrm{~g} / \mathrm{d})$.

Only $3 \cdot 4 \%$ of the population met the recommendation of consuming at least $450 \mathrm{~g}$ dairy or Ca-enriched soya products daily. The mean daily intake of dairy and soya products was only $35 \%$ of the lower limit of the recommendation.

However, the recommendation for cheese intake was more easily met: $68 \cdot 1 \%$ of the population consumed at least $20 \mathrm{~g}$ cheese daily but a quarter of the population exceeded the recommendation by eating more than $40 \mathrm{~g} / \mathrm{d}$. Men in particular exceed the recommendation $(32 \cdot 3 \% v$. $17 \cdot 2 \%$ for women).

The mean intake of meat, fish, eggs and meat substitutes exceeded the upper limit of the recommendation by 1.6 times. Only $11.9 \%$ of the population met the recommendation and consumed less than $100 \mathrm{~g}$ of these products daily. Nevertheless, more than $20 \%$ of women had an intake lower than $100 \mathrm{~g} / \mathrm{d}$ and this amounted to $44 \cdot 2 \%$ in the age group $15-18$ years.
The mean intake of fish and crustaceans was below the recommended daily intake of $30 \mathrm{~g} / \mathrm{d}$. Nearly $70 \%$ of the Belgian population did not meet this recommendation. The female population was most at risk as nearly $75 \%$ of women did not consume enough fish or crustaceans.

Regarding fats, a comparison is possible only with the recommended intake for spreadable fats (maximum of $5 \mathrm{~g}$ per slice of bread). In fact, the recommendation states that people should moderate their fat consumption. Compared with the upper limit of bread consumption $(420 \mathrm{~g} / \mathrm{d})$, only $6 \cdot 1 \%$ of the population exceeded the recommendation of using more than $60 \mathrm{~g}$ spreadable fats/d.

Because nutrient-poor, energy-dense foods are not necessary for a healthy diet, the recommended daily intake is set at $0 \mathrm{~g} / \mathrm{d}$. The majority of the population $(92 \cdot 0 \%)$ consumed more than $100 \mathrm{~g}$ of these products daily and $36 \cdot 1 \%$ consumed more than $500 \mathrm{~g} / \mathrm{d}$. Without including alcohol, these percentages are $75 \cdot 9 \%$ and $13 \cdot 2 \%$, respectively.

\section{Discussion}

\section{Main results: food intakes deviate from recommendations}

Several major findings have emerged from the present study. Most importantly, the overall food intake of the Belgian population does not comply with the FBDG. The consumption of food products from the triangle tip is excessive while the average daily portions consumed from all other groups, except for meat products and substitutes, cheese, potatoes, rice and pasta, are below the recommendations.

The percentage of the population complying with the different food-based recommendations is low. With the exception of spreadable fat, cheese and potatoes/rice/ pasta, not one of the recommendations is met by even half of the population. 
For vegetables, fruits, dairy products and energy-dense, nutrient-poor foods, the percentage of the population meeting the recommendations is below $10 \%$. It should be noted that these apparent differences between intake and recommendations could be due to a certain extent to inadequate reporting (e.g. under-reporting). The percentage of energy under-reporting, using the equation of Goldberg et al. ${ }^{(25)}$, is $14 \%$ for women and $26 \%$ for men.

Fruit and vegetable consumption is lowest in the youngest age group although their recommended fruit intake is higher than for other age groups. Their consumption of energy-dense, nutrient-poor foods, in particular soft drinks, is higher than in the other age groups. However, adolescents consume more potatoes, pasta and dairy products than the older age groups and they use less spreadable fats. In a study on Flemish adolescents (13-18 years) in 1997, it was found that their macronutrient intakes deviated significantly from the recommendations ${ }^{(26)}$ and that their nutritional profile could be substantially improved by decreasing the portion sizes of fresh meat, high-fat margarine, high-fat cheese, preprepared baked goods, snack foods and processed foods including fast foods ${ }^{(27)}$.

There are also some gender differences: men consume more animal products like meat, fish, eggs, spreadable fats and dairy products, and more starchy products than women. Women consume more fruits.

Education level differences are only minor. Vegetable and cheese intake increases with education level, while the intake of spreadable fat and meat products decreases with education level.

Physical activity in Belgium is low: only about a quarter of the population is active enough to experience healthenhancing effects.

\section{Comparison with other studies}

In 2003 a dietary survey was organised in The Netherlands among 19-30-year-olds ( $n$ 750). As in the BNFCS, two $24 \mathrm{~h}$ recalls were taken and EPIC-SOFT was used ${ }^{(28)}$. The vegetable consumption in Belgium (age group 19-29 years) was low but still higher than in The Netherlands (125 (sD 43) g/d v. 100 (SD 68) g/d in The Netherlands). The fruit intake in Belgium was 85 (SD 69) g/d v. 98 (SD 109) $\mathrm{g} / \mathrm{d}$ in The Netherlands. However, there is a noticeable difference in dairy consumption: the dairy consumption in Belgium (212 (SD 154) g/d) was more or less half of the dairy consumption in The Netherlands (391 (SD 297) $\mathrm{g} / \mathrm{d}$ ), but the cheese consumption was about the same (29 (sD 19) g/d v. 32 (sD 31) g/d for The Netherlands).

In France, a National Nutrition and Health Survey was implemented in 2006 among participants aged 18-74 years $(n 3115)^{(29)}$. Three randomly distributed $24 \mathrm{~h}$ recalls were used for dietary intake collection. According to the French recommendation for fruit and vegetable intake, at least $400 \mathrm{~g}$ should be consumed daily. Some $42 \cdot 8 \%$ of the French population complied with this recommendation.
More women complied with this recommendation than men and, for both genders, the percentage of persons complying with this recommendation increased with age.

The consumption of vegetables, fruits, dairy products, soya products, fat and meat was compared among ten European countries participating in the EPIC study ${ }^{(30-34)}$. Subjects were 35-74 years old ( $n 35$ 955). Southern countries had the highest fruit and vegetable consumption (e.g. vegetables, Greece: $207 \mathrm{~g} / \mathrm{d}$ for women and $270 \mathrm{~g} / \mathrm{d}$ for men), while the lowest intake was seen in The Netherlands and Scandinavia (e.g. vegetables, Sweden: $131 \mathrm{~g} / \mathrm{d}$ for women and $122 \mathrm{~g} / \mathrm{d}$ for men) ${ }^{(30)}$. A high consumption of dairy products was reported in Spain, the UK (p.e. $366 \mathrm{~g} / \mathrm{d}$ for women and $408 \mathrm{~g} / \mathrm{d}$ for men), The Netherlands, Sweden and Denmark. A somewhat lower consumption was reported in Greece $(187 \mathrm{~g} / \mathrm{d}$ for both genders) and Italy ${ }^{(31)}$.

Only a rough comparison can be made with results of other dietary surveys because differences in food intake can be the consequence of different factors: demographic characteristics of the study population and differences in item composition of the food groups.

\section{Metbodological aspects}

Although the EFCOSUM methodology was followed for the present survey, there are some limitations. First, no information was gathered about the dietary intake of children ( $<15$ years). A new survey is foreseen from 2009 onwards to assess food intake in children. In 2002/2003 the dietary intake of Flemish pre-school children was assessed using a $3 \mathrm{~d}$ estimated record ( $n$ 661). The main conclusions were similar to those of the present adult study: mean daily intakes of nearly all food groups were below minimum recommendations, except for potatoes, cheese and meat products ${ }^{(35)}$.

Second, although great efforts were made to select a representative sample of the Belgian population, the participation rate was below 50\%. (Un)willingness to participate may result in a selection bias, but no additional information on the non-responders is available. Non-responders were replaced by a selected reserve person of the same gender, age and living in a household of the same size and in the same commune as the originally selected person.

Third, some authors argue that while the development of FBDG has contributed to the understanding of the role of specific foods in achieving optimal health, the impact of these guidelines on human health has been limited ${ }^{(36)}$. Nevertheless, the BNFCS can be a practical tool for public health policy. In 2006, as a result of the first BNFCS, the Belgian government started a campaign to improve the dietary habits of the population: the Belgian plan for nutrition and health, consisting of several working groups, which offer concrete, visible and coordinated actions on a national level to improve the dietary habits and health status of the population. 
To be able to further evaluate the dietary intake of the Belgian population, a (semi-) continuous monitoring system should be organised. Such a system is already in place in other European countries such as The Netherlands ${ }^{(37)}$. Regular monitoring will allow measurement of time trends and the fine-tuning of actions taken to improve health status on a national and regional level.

In conclusion, the present study showed that the food intake of the Belgian population deviates significantly from the FBDG and differs substantially between age and sex groups. Further efforts are necessary to improve the Belgian food pattern, in particular among the youngest age group, in order to better prevent diet-related diseases. In addition, continuous or regular monitoring is crucial to enable trend analyses and to plan effective education and intervention strategies.

\section{Acknowledgements}

The authors declare not having any conflicts of interest. The authors acknowledge the dietary support from Mia Bellemans, Mieke De Maeyer, Kadija El Moumni and Davy Van Steenkiste. Special thanks go to the respondents and dietitians during the field work. The survey was funded by the Federal Ministry of Health, Food Chain Safety and Environment.

S.V. drafted the manuscript and did some additional analyses relevant for the paper. S.D.V., I.H. and M.M. coordinated the field work of the survey and contributed to the data input and the data analyses of the survey. E.T. contributed to the data analyses of the survey. S.D.H., G.D.B., M.K. and A.L. participated in the design of the survey. H.V.O. contributed to the design of the survey and the data analyses and was the general coordinator of the survey. All authors made a substantial contribution in critically revising the manuscript. All authors read and approved the final manuscript.

\section{References}

1. BIRNH (1989) BIRNH - The Belgian Interuniversity Research on Nutrition and Health Study group. Acta Cardiol 64, 89-194.

2. World Health Organization (1998) Preparation and Use of Food-based Dietary Guidelines. Report of a Joint FAO/WHO Consultation. WHO Technical Report Series no. 880, pp. i-108. Geneva: WHO.

3. Aranceta J \& Serra-Majem L (2001) Dietary guidelines for the Spanish population. Public Health Nutr 4, 1403-1408.

4. Valsta LM (1999) Food-based dietary guidelines for Finland - a staged approach. Br J Nutr 81, Suppl. 2, S49-S55.

5. Kersting M, Alexy U \& Clausen K (2005) Using the concept of food based dietary guidelines to develop an optimized mixed diet (OMD) for German children and adolescents. J Pediatr Gastroenterol Nutr 40, 301-308.

6. Koenig J \& Elmadfa I (1999) Food-based dietary guidelines - the Austrian perspective. Br J Nutr 81, Suppl. 2, S31-S35.
7. Flynn MA \& Kearney JM (1999) An approach to the development of food-based dietary guidelines for Ireland. Br J Nutr 81, Suppl. 2, S77-S82.

8. Lowik MR, Hulshof KF \& Brussaard JH (1999) Food-based dietary guidelines: some assumptions tested for The Netherlands. Br J Nutr 81, Suppl. 2, S143-S149.

9. Turrini A, Leclercq C \& D'Amicis A (1999) Patterns of food and nutrient intakes in Italy and their application to the development of food-based dietary guidelines. Br J Nutr 81, Suppl. 2, S83-S89.

10. Moschandreas J \& Kafatos A (1999) Food and nutrient intakes of Greek (Cretan) adults. Recent data for foodbased dietary guidelines in Greece. BrJ Nutr 81, Suppl. 2, S71-S76.

11. McCarthy SN, Robson PJ, Livingstone MB, Kiely M, Flynn A, Cran GW \& Gibney MJ (2006) Associations between daily food intake and excess adiposity in Irish adults: towards the development of food-based dietary guidelines for reducing the prevalence of overweight and obesity. Int $J$ Obes (Lond) 30, 993-1002.

12. Hoge Gezondheidsraad (2006) Voedingsaanbevelingen voor België, no. 7145-2. Brussels: Hoge Gezondheidsraad.

13. Commission of the European Communities (1993) Nutrient and Energy Intakes for the European Community. Reports of the Scientific Committee for Food, Food Science and Techniques Series no. 31. Luxemburg: Commission of the European Communities.

14. Absolonne J, Sirjacobs F, Guggenbühl N \& Colin N (1998) La pyramide alimentaire ou quand les nutriments deviennent réalité. Health Food 28, 1-5.

15. Vlaams Instituut voor Gezondheidspromotie (2004) De voedingsdrieboek: een praktische voedingsgids. Brussels: Vlaams Instituut voor Gezondheidspromotie.

16. Vlaams Instituut voor Gezondheidspromotie (2005) De actieve voedingsdriehoek. Brussels: Vlaams Instituut voor Gezondheidspromotie.

17. Brussaard JH, Johansson L \& Kearney J (2002) Rationale and methods of the EFCOSUM project. Eur J Clin Nutr 56, Suppl. 2, S4-S7.

18. De Vriese S, De Backer G, De Henauw S, Huybrechts I, Kornitzer K, Leveque A, Moreau M \& Van Oyen H (2005) The Belgian food consumption survey: aims, design and methods. Arch Public Health 63, 1-16.

19. International Physical Activity Questionnaire (2005) Guidelines for data processing and analysis of the international physical activity questionnaire. http://www.ipaq.ki.se

20. Slimani N \& Valsta L (2002) Perspectives of using the EPICSOFT program in the context of pan-European nutritional monitoring surveys: methodological and practical implications. Eur J Clin Nutr 56, Suppl. 2, S63-S74.

21. Nusser SM, Carriquiry AL, Dodd KW \& Fuller WA (1996) A semiparametric transformation approach to estimating usual daily intake distributions. J Am Stat Assoc 91, 1440-1449.

22. Food and Nutrition Board, Institute of Medicine (2003) Dietary Reference Intakes: Applications in Dietary Assessment. Washington, DC: National Academy Press.

23. Guenther PM, Kott PS \& Carriquiry AL (1997) Development of an approach for estimating usual nutrient intake distributions at the population level. J Nutr 127, 1106-1112.

24. Iowa State University (2006) C-side. http://www.cssm.iastate.edu/software/cside.html

25. Goldberg GR, Black AE, Jebb SA, Cole TJ, Murgatroyd PR, Coward WA, Prentice AM. Critical evaluation of energy intake data using fundamental principles of energy physiology: 1. Derivation of cut-off limits to identify under-recording. Eur J Clin Nutr 45, 569-581.

26. Matthys C, De Henauw S, Devos C \& De Backer G (2003) Estimated energy intake, macronutrient intake and meal pattern of Flemish adolescents. Eur J Clin Nutr 57, 366-375. 
27. Matthys C, De Henauw S, Bellemans M, De Maeyer M \& De Backer G (2006) Sources of saturated fatty acids in Belgian adolescents' diet: implications for the development of food-based dietary guidelines. BrJ Nutr 95, 546-554.

28. Hulshof KF \& Ocke M (2004) Resultaten van de Voedselconsumptiepeiling 2003. RIVM rapport 350030002/2004, pp. 1-111. Bilthoven: RIVM.

29. Institut de Veille sanitaire UdP1 (2007) Unité de surveillance et d'épidémiologie nutritionelle (Usen). Etude nationale nutrition santé (ENNS, 2006). Situation nutritionelle en France en 2006 selon les indicateurs d'objectif et les repères du Program national nutrition santé (PNNS). Paris: Institut de Veille sanitaire.

30. Agudo A, Slimani N, Ocke MC et al. (2002) Consumption of vegetables, fruit and other plant foods in the European Prospective Investigation into Cancer and Nutrition (EPIC) cohorts from 10 European countries. Public Health Nutr $\mathbf{5}$, 1179-1196.

31. Hjartaker A, Lagiou A, Slimani N et al. (2002) Consumption of dairy products in the European Prospective Investigation into Cancer and Nutrition (EPIC) cohort: data from 35955 24-hour dietary recalls in 10 European countries. Public Health Nutr 5, 1259-1271.
32. Linseisen J, Kesse E, Slimani N et al. (2002) Meat consumption in the European Prospective Investigation into Cancer and Nutrition (EPIC) cohorts: results from 24-hour dietary recalls. Public Health Nutr 5, 1243-1258.

33. Linseisen J, Bergstrom E, Gafa L et al. (2002) Consumption of added fats and oils in the European Prospective Investigation into Cancer and Nutrition (EPIC) centres across 10 European countries as assessed by 24-hour dietary recalls. Public Health Nutr 5, 1227-1242.

34. Keinan-Boker L, Peeters PH, Mulligan AA et al. (2002) Soy product consumption in 10 European countries: the European Prospective Investigation into Cancer and Nutrition (EPIC) study. Public Health Nutr 5, 1217-1226.

35. Huybrechts I, Matthys C, Vereecken C, Maes L, Temme EHM, Van Oyen H et al. (2008) Food intakes by preschool children in Flanders compared with recommendations. BrJ Nutr (In the Press).

36. Smitasiri S \& Uauy R (2007) Beyond recommendations: implementing food-based dietary guidelines for healthier populations. Food Nutr Bull 28, Suppl., S141-S151.

37. Ocke M, Hulshof KF, Bakker MI, Stafleu A \& Streppel MT (2005) Naar een nieuw Nederlands voedingspeilingsysteem. RIVM rapport $350050001 / 2005$, pp. 1-80. Bilthoven: RIVM. 